\title{
https://doi.org/10.46813/2021-133-086 \\ CALCULATION OF THE MOLIÈRE RADIUS FOR VARIOUS CONFIGURATIONS OF AN ELECTROMAGNETIC SAMPLING CALORIMETER ECaL SPD NICA
}

\author{
V.E. Kovtun ${ }^{1}$, T.V. Malykhina ${ }^{1,2}$ \\ ${ }^{1}$ V.N. Karazin Kharkiv National University, Kharkiv, Ukraine; \\ E-mail: malykhina@karazin.ua; \\ ${ }^{2}$ National Science Center "Kharkov Institute of Physics and Technology”, Kharkiv, Ukraine
}

One of the main tasks of the electromagnetic calorimetry of the SPD setup is effective $\pi^{0}-\gamma$ separation in the energy range from $50 \mathrm{MeV}$ to $10 \mathrm{GeV}$. Therefore, the current task is to optimize the design of the module cells in order to improve the physical parameters of the $\mathrm{ECaL}$ calorimeter. The Molière radius is determined in this work by the Monte Carlo method using Geant4 toolkit for various cell configurations of the calorimeter module. The results obtained in this work will be taken into account in the further development of the detecting systems of the ECaL SPD NICA.

PACS: 07.05.Tp, 29.40.Vj, 02.70.Uu

\section{INTRODUCTION}

The physical program [1] of the SPD facility for studying the spin structure of nucleons and other polarization phenomena using colliding beams of longitudinally and transversely polarized protons and deuterons of the NICA collider has been developed to date.

Electromagnetic calorimeter ECaL SPD has a $\sim 4 \pi \pi$ structure. The calorimeter must have an energy resolution for photons and electrons of order $5 \% / \sqrt{\mathrm{E}}[\mathrm{GeV}]$ in the range from $50 \mathrm{MeV}$ to $10 \mathrm{GeV}$. Good energy resolution is required for identifying and quantifying the energies of single photons and neutral pions.

The calorimeter module also has high requirements in terms of spatial resolution. Good two-part spatial separation will allow the identification of the $\pi^{0}$-meson against the background of a large number of photons in polarized beam nucleons collisions. This problem is reliably solved at energies up to $500 \mathrm{MeV}$ due to the large scattering angle of gamma quanta. However, it is necessary to decrease the cell size for efficient identification of $\pi^{0}$ mesons at high energies. This means that the lateral dimension of the calorimeter module cell should be about one Molière radius for reliable determination of the photon energy. Long-term stability is essential for polarization measurements with $\pi^{0}$ reconstruction, especially in an end-cup calorimeter. Calorimeter instability can lead to incorrect asymmetry values. Cost estimates and technical feasibility should also be taken into account when choosing level of detail since more cells lead to higher manufacturing costs for calorimeter and readout electronics.

The module prototype with a cell size of $55 \times 55 \times 400 \mathrm{~mm}$ is shown in Fig. 1 .

Each cell is optically separated and has its own readout system.

The calorimeter sampling structure is a set of alternating lead absorber and plastic scintillator plates.

Considerable attention was paid to various issues of optimization of the SPD calorimeter module, as well as possible ways to improve its parameters $[2,3]$.

The main goal of our work is to determine the Molière radius for various configurations of the $\mathrm{ECaL}$
SPD electromagnetic calorimeter by the Monte Carlo method.

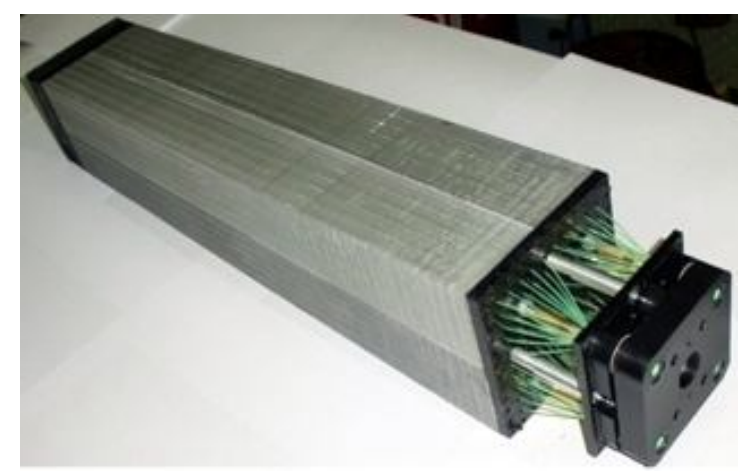

Fig. 1. Photo of a single module consisting of 4 cells with 220 layers of scintillator and absorber

\section{THEORETICAL APPROARCH}

High-energy electrons, positrons, gamma quanta, $\pi^{0}$ mesons form an electromagnetic shower when they hit the calorimeter. The transverse dimensions of the shower are characterized by the Molière radius $\left(\mathrm{R}_{\mathrm{M}}\right)$.

The lateral dimensions of the shower are due to secondary processes of electron-positron pair production, positron annihilation, and multiple scattering of electrons and positrons in the calorimeter material.

The lateral width of an electromagnetic cascade is mainly determined by multiple scattering and can be described in units of the Molière radius $\mathrm{R}_{\mathrm{M}}[4,5]$ :

$$
R_{M} \approx \frac{21.2 \mathrm{MeV}}{E_{C}} X_{0}
$$

where $E_{C}$ is the critical energy, $X_{0}$ is the radiation length of a material.

In a material containing a weight fraction $\mathrm{w}_{\mathrm{j}}$ of the element with critical energy $E_{C j}$ and radiation length $X_{0 j}$, the Molière radius $R_{M}$ is given by

$$
\frac{1}{R_{M}} \approx \frac{1}{E_{S}} \cdot \sum_{j} \frac{w_{j} E_{C j}}{X_{0 j}}
$$

where $\mathrm{j}$ is the index of a material and $\mathrm{E}_{\mathrm{S}} \approx 21.2 \mathrm{MeV}$ [4].

Calculations of more accurate $R_{M}$ values are required in calorimetry, especially for the problem of $\pi^{0}$-mesons 
identifying. Detailed Monte Carlo shower simulations using a large number of events can obtain these $R_{M}$ values.

The task becomes much more difficult in composite structures due to the dependence on structure and material. There can be also a correlation between the longitudinal and transverse components of the shower as well as significant fluctuations in the absorbed energy. Long calculation time may be needed to obtain good accuracy.

Parametrization of electromagnetic showers in sampling calorimeters is presented in [6]. This parameterization allows us to significantly reduce the computation time without accuracy loss. Such parametrizations were widely used to calculate the parameters of calorimeters, since they took into account the features of sampling calorimeters, in particular, the transition effect

However, it should be noted that G. Grindhammer, S. Peters [6] found these approximations using the Monte Carlo method (Geant3) for the specific conditions of the H1 setup [7], where liquid argon was used as a scintillator. The parameters of a shower in a homogeneous medium and the corresponding empirical formulas that describe it were used as a first approximation. The approximations were checked later for sampling calorimeter media (Fe-LAr, Cu-Sc, W-LAr, Pb-LAr, U-Sc) at high energies of incident particles. Therefore, we were interested in regions up to $10 \mathrm{GeV}$ and simulation conditions different from [6].

We used significantly lower cut energies, as well as refined models of physical processes in the PhysicsLists class (Geant4 toolkit) [8] for simulation.

\section{METHOD FOR THE MOLIÈRE RADIUS CALCULATION}

A program developed on the basis of the Monte Carlo method using the Geant4 toolkit will allow us to avoid oversimplification, by implementing the important cross section data and a low cut energy, in contrast to theoretical works (for example, [4]).

The Molière radius $\mathrm{R}_{M}$ for a certain substance is determined by the radius of a cylinder of this substance in which, on average, about $90 \%$ of the electromagnetic shower is absorbed [5]. On average, about $99 \%$ of the shower energy is contained in a cylinder of radius $\sim 3.5 \cdot \mathrm{R}_{\mathrm{M}}$.

A computer program was developed using the Geant 4 toolkit to calculate the values of the absorbed energy in a cylinder with variable parameters. The variable parameters are diameter, height and materials of the calorimeter. We have determined the outer cylindrical volume of the same material in order to avoid energy leaks, but preserve the rescattering of particles. The cylinders are made extensively long to avoid longitudinal energy leakage. The incoming beam particle is placed in the center of the inner cylinder to avoid energy leaks from the front end of the cylinder.

The method for determining the radius is as follows. We vary the radius of the inner cylinder in order to obtain $\sim 90 \%$ of the shower energy at the total absorption peak as a result of the simulation. We assume that the value of the ECal calorimeter Molière radius is the value of the inner cylinder radius at which about $90 \%$ of the energy is absorbed. The total absorption peak formed by $\sim 90 \%$ of the deposited energy in the inner cylinder will be asymmetrical due to lateral energy leaks into the outer cylinder.

The developed program contains visualization modules that are necessary for a visual presentation of the ongoing processes, as well as modules necessary for tracking events for the purpose of further statistical processing.

The peak was approximated by the Das function [9] using the ROOT package [10], from which the mean energy $\mathrm{E}_{\text {mean }}$ and standard deviation $\sigma$ were obtained.

\section{MODELING THE MOLIERE RADIUS IN HOMOGENEOUS MEDIA}

The values of the Molière radii in homogeneous media were determined in order to test this approach and verify the developed computer model. The calorimeter layers are composed of lead and polystyrene; therefore, these substances are chosen as homogeneous media for testing the developed program. The calculations were performed with a statistical accuracy of $1 \%$ for incident electrons or photons in energy range from $100 \mathrm{MeV}$ to $10 \mathrm{GeV}$.

The RangeCut parameter is set to $10 \mu \mathrm{m}$. The cut energy in lead is $58 \mathrm{keV}$ for electrons, $56.7 \mathrm{keV}$ for positrons, and $5.98 \mathrm{keV}$ for gamma quanta. In the case of polystyrene, the threshold energy is $15.2 \mathrm{keV}$ for electrons, $15 \mathrm{keV}$ for positrons, and $0.1 \mathrm{keV}$ for gamma quanta.

The most suitable model of Geant 4 physical processes for electromagnetic shower simulation is the emstandard opt3 model in the PhysicsList class. This model allows the most accurate simulation of processes occurring in the substance of an electromagnetic calorimeter during the shower progression [11]. Therefore, this model was chosen to carry out a series of calculations.

Let us consider the features of these calculations using the example of lead, for which $\mathrm{R}_{\mathrm{M}}=16 \mathrm{~mm}$, according to [5]. We will call it the inner cylinder with radius $R_{1}$, which is placed into the outer cylinder with the radius $\mathrm{R}_{2}=3.5 \cdot \mathrm{R}_{1}$.

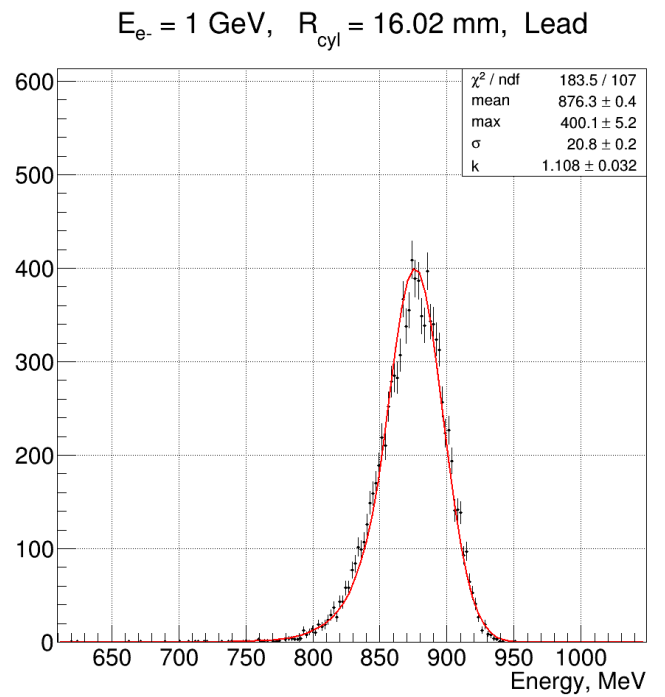

Fig. 2. Deposited energy in a lead $\left(R_{M}=16 \mathrm{~mm}\right)$ cylinder for incident electrons, $E=1 \mathrm{GeV}$

The spectrum of the deposited energy in the inner cylinder for incident electrons with energy of $1 \mathrm{GeV}$ is pre- 
sented in Fig. 2. The peak is approximated by the Das curve [9], which has a good convergence.

The average value $E_{\text {mean }}$ is $(876.3 \pm 20.8) \mathrm{MeV}$ for the incident particle energy $\mathrm{E}_{\mathrm{e}-}=1 \mathrm{GeV}$. The $\chi 2 / \mathrm{ndf}$ value is $\sim 1$. The resulting value corresponds to $\sim 87.6 \%$ of the incident particles energy.

Similar calculations were carried out for polystyrene.

The result for incident electrons with energy $\mathrm{E}_{0}=1 \mathrm{GeV}$ and inner radius $\mathrm{R}_{1}=\mathrm{R}_{\mathrm{M}}=94 \mathrm{~mm}$ is $\mathrm{E}_{\text {mean }}=$ (877.5 \pm 39$) \mathrm{MeV}$. This result corresponds to $\sim 87.7 \%$ of the incident particles energy (Fig. 3).

Therefore, the model developed by us is applicable to the materials of the ECaL calorimeter.

The next step is checking the model in the case of a sampling calorimeter.

$$
E_{e-}=1 \mathrm{GeV}, R_{\text {cyl }}=94 \mathrm{~mm} \text {, Polystyrene }
$$

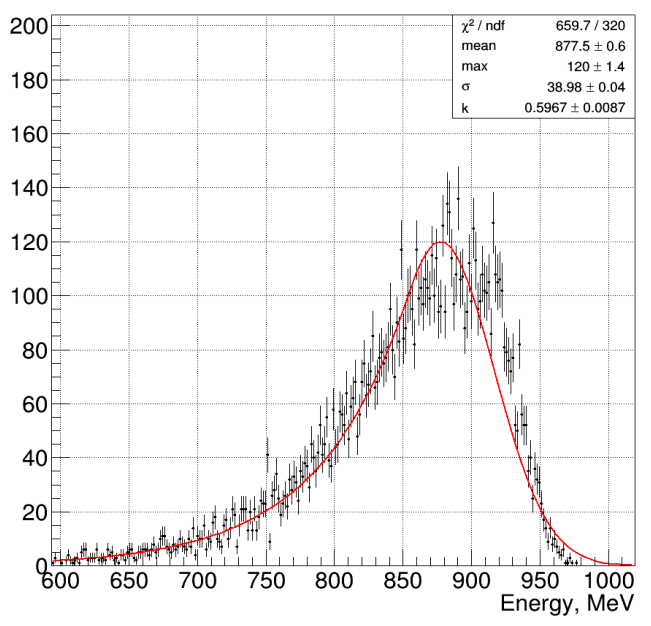

Fig. 3. Deposited energy in a polystyrene $\left(R_{M}=94 \mathrm{~mm}\right)$ cylinder for incident electrons, $E=1 \mathrm{GeV}$

\section{MODELING THE MOLIÈRE RADIUS FOR SAMPLING CALORIMETERS \\ 4.1. CALCULATION OF THE MOLIÈRE RADIUS FOR THE ZEUS CALORIMETER}

The ZEUS calorimeter consists of $2.6 \mathrm{~mm}$ thick polystyrene and $3.3 \mathrm{~mm}$ thick uranium layers. The Molière radius of the ZEUS calorimeter is $\sim 20 \mathrm{~mm} \mathrm{[12].}$

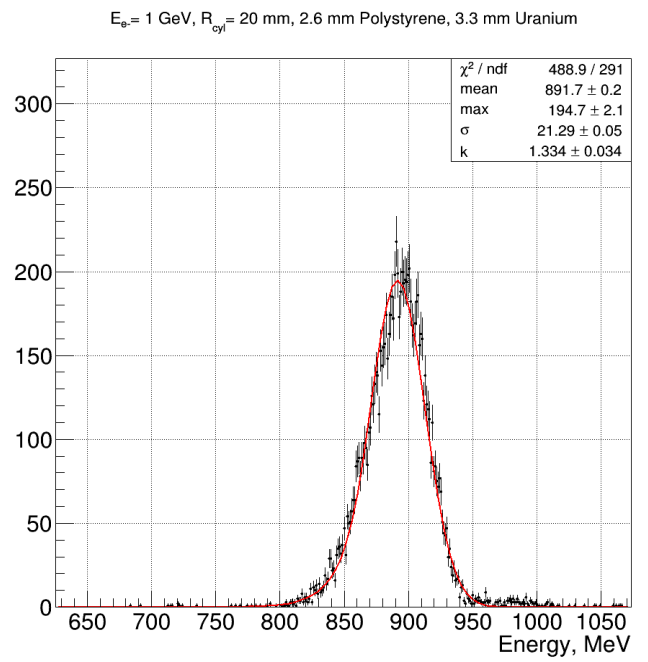

Fig. 4. Deposited energy in the ZEUS calorimeter $\left(R_{M}=20 \mathrm{~mm}\right)$ [12] for incident electrons, $E=1 \mathrm{GeV}$
The calculation of the Molière radius for the ZEUS facility was carried out to check the applicability of our program in the case of a sampling calorimeter. The energy of incident electrons was $1 \mathrm{GeV}$. The value of the deposited energy is shown in Fig. 4.

The mean value of the deposited energy is $(891 \pm 21.3) \mathrm{MeV}$. This result corresponds to the definition of the Molière radius since it is $\sim 89 \%$ of the incident particles energy.

\subsection{CALCULATION OF THE MOLIÈRE RADIUS FOR THE KOPIO CALORIMETER}

Similar calculations were carried out for the sampling calorimeter of the KOPIO facility [13].

These calculations can be used to check the adequacy of our program model because the KOPIO calorimeter layers consist of materials that were used in the development of the NICA SPD electromagnetic calorimeter.

The KOPIO calorimeter consists of alternating layers of lead and polystyrene. Lead is $0.275 \mathrm{~mm}$ thick and polystyrene is $1.5 \mathrm{~mm}$ thick. The Molière radius of the KOPIO calorimeter is $\sim 60 \mathrm{~mm}$ [13].

The deposited energy in the KOPIO calorimeter is $(871 \pm 24) \mathrm{MeV}$ for primary electrons with $\mathrm{E}_{0}=1 \mathrm{GeV}$. This value is obtained as a result of simulation using our model. The result corresponds to approximately $87 \%$ of energy of incident particles.

The deposited energy spectrum for a cylinder with a radius equal to one Molière radius and having a sampling structure of the KOPIO calorimeter is shown in Fig. 5.

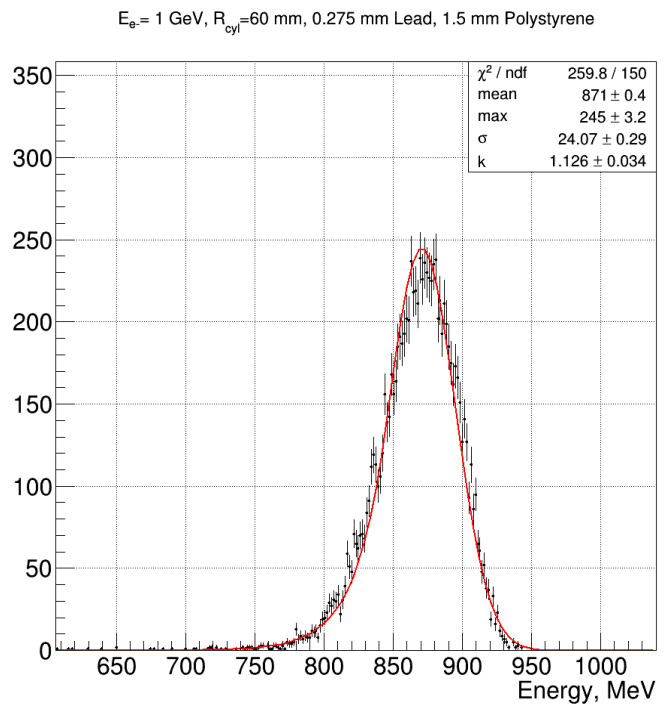

Fig. 5. Deposited energy spectrum for a cylinder with a radius of $1 R_{M}$ of the KOPIO calorimeter sampling structure

The performed model verification makes it possible to use this calculation technique to determine the Molière radius in the case of the NICA SPD sampling calorimeter.

\section{CALCULATION OF THE MOLIÈRE RADIUS FOR THE SPD SAMPLING CALORIMETER}

A preliminary estimate of the Molière radius was carried out according to (2). A radius of $42.3 \mathrm{~mm}$ was obtained for $0.5 \mathrm{~mm}$ lead in a sandwich structure of the ECal calorimeter. 
Monte Carlo calculations were performed for various values of the calorimeter radius in the range from 40 to $60 \mathrm{~mm}$. These calculations of the Molière radius of the NICA SPD ECal facility were carried out using the developed computer program based on Geant4 toolkit. The geometrical parameters of the ECaL calorimeter were determined in the DetectorConstruction class. All other modules of the validated program were unchanged. The number of primary electrons $\mathrm{N}_{\text {events }}$ was equal to $10^{4}$. The thickness of the lead layer was varied from 0.3 to $0.5 \mathrm{~mm}$ according to the requirements [1].

As a result of modeling it turned out that the value of the deposited energy in the calorimeter is approximately $87.2 \%$ of the primary particles energy at a radius of $46 \mathrm{~mm}$ (Fig. 6). The $99 \%$ of energy deposited in the calorimeter were within radius of 3.5 radii of $R_{M}=46 \mathrm{~mm}$. Similar calculations were carried out for positrons and gamma quanta.

We can assume that the Molière radius of the ECaL electromagnetic sampling calorimeter of the NICA SPD setup is $46 \mathrm{~mm}$ for $0.5 \mathrm{~mm}$ lead thick. Our assumptions are based on the results of the program validation.

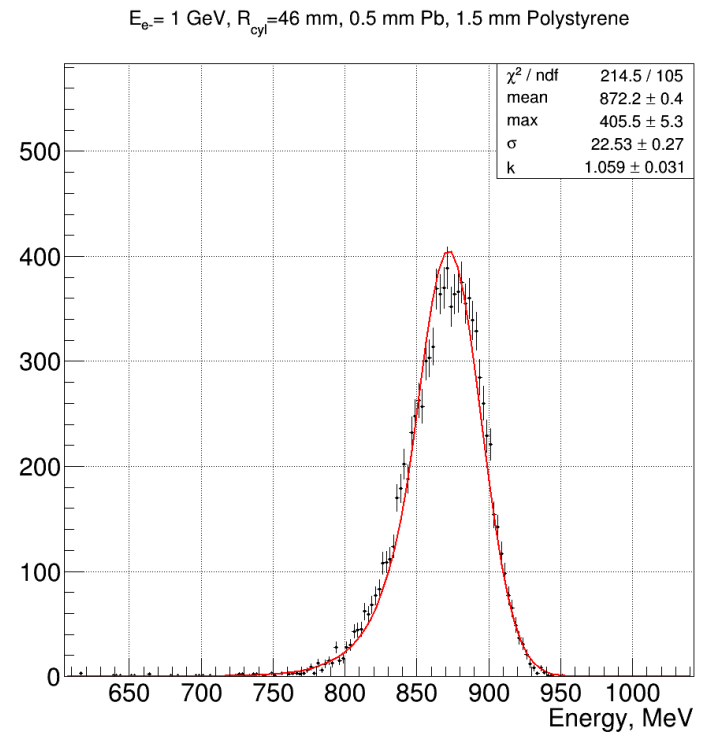

Fig. 6. Energy spectrum of the deposited

in the calorimeter energy for primary electrons

with $E=1 \mathrm{GeV}$. Case 1: $0.5 \mathrm{~mm}$ lead layer, $1.5 \mathrm{~mm}$ polystyrene layer. Radius $=46 \mathrm{~mm}$

Similar calculations were carried out for 0.3 and $0.4 \mathrm{~mm}$ lead thicknesses. The values of the Molière radius $R_{M}$ are given in Table for the ECaL SPD configurations proposed in [1].

Values of the Molière radius for different thickness values of the lead absorber

\begin{tabular}{|c|c|c|}
\hline$\Delta \mathrm{X}_{\mathrm{Pb}}, \mathrm{mm}$ & $\begin{array}{c}\mathrm{R}_{\mathrm{M}}, \mathrm{mm} \\
\text { from (2) }\end{array}$ & $\begin{array}{c}\mathrm{R}_{\mathrm{M}}, \mathrm{mm} \\
(\mathrm{Geant} 4)\end{array}$ \\
\hline 0.5 & 42.3 & 46 \\
\hline 0.4 & 46.4 & 51 \\
\hline 0.3 & 52.0 & 57 \\
\hline
\end{tabular}

The statistical error of calculations for $\mathrm{N}=10^{4}$ primary particles is $1 \%$. The error in determining the Molière radius $\Delta \mathrm{R}_{\mathrm{M}}$ is slightly larger than the statistical calculation error because it depends on the primary particles energy.
The error in determining the Molière radius $\Delta R_{M}$ decreases at high incident particle energies $(\sim 100 \mathrm{GeV})$ due to a decrease in fluctuations of energy leaks from the calorimeter volume.

\section{CONCLUSIONS}

The values of the Molière radii of $\mathrm{Pb} / \mathrm{PS}$ various configurations for the SPD NICA electromagnetic sampling calorimeter were obtained using simulation based on Geant4 toolkit.

These values were not obtained from the radial distribution of the electromagnetic shower. Instead, we calculated the Molière radius from the spatial distribution of $\sim 90 \%$ of the primary particles deposited energy. In this case the results are less dependent on the shape of energy spatial distribution function. Previously, these functions were obtained mainly empirically by fitting experimental data. The reliability of these functions strongly depends on both the experimental or simulation conditions and the bias of authors. The error in determining the Molière radius has a clear physical meaning when calculating by our method. It is determined by energy leaks fluctuations from the calorimeter volume with $R_{M}$ radius into the outer infinite volume. The $\mathrm{R}_{\mathrm{M}}$ calculation error decreases when the shower energy increases because the relative error of the total absorption peak decreases.

\section{REFERENCES}

1. The SPD Collaboration. Conceptual design of the Spin Physics Detector // arXiv:2102.00442v1, 2021, 191 p. https://arxiv.org/abs/2102.00442

2. O.P. Gavrishchuk, V.E. Kovtun, T.V. Malykhina. Simulation Study of Energy Resolution of the Electromagnetic Shashlyk Calorimeter for Different of Layers and Absorber Combinations // East Eur. J. Phys. 2020, №3, p. 73-80. https://doi.org/ 10.26565/2312-4334-2020-3-09

3. O.P. Gavrishchuk. The sampling electromagnetic calorimeter with longitudinal segmentation // Calorimetry for the High Energy Frontier, November, 2019, Fukuoka, Japan, 28 p. https://indico.cern.ch/event/818783/contributions / 3598505/attachments/1950394/3237581/2_section_e cal.pdf

4. B. Rossi and K. Greisen. Cosmic-Ray Theory // Rev. Mod. Phys. 1941, № 13, p. 240.

5. Particle Data Group. Review of Particle Physics // Progress of Theoretical and Experimental Physics. 2020, № 8, 2093 p. https://doi.org/10.1093/ ptep/ptaa104

6. G. Grindhammer, S. Peters. The Parameterized Simulation of Electromagnetic Showers in Homogeneous and Sampling Calorimeters. 2000. https://arxiv.org/abs/hep-ex/0001020.

7. H1 Collaboration // Technical Proposal for the H1 Detector, Hamburg: DESY, 1986, 276 p.

8. J. Allison. Recent developments in GEANT4 // Nuclear Instruments and Methods in Physics Research A, 2016, v. 835, p. 186-225. https://doi.org/10.1016/ j.nima.2016.06.125

9. S. Das. A simple alternative to the Crystal Ball function. 2016. https://arxiv.org/abs/1603.08591 
10.ROOT6, Data Analysis Framework. Instruments and Methods in Physics Research A. https://root.cern.ch 1991, v. 309, p. 77-100.

11. Geant4 Physics List Guide. 2021, 69 p. 13. G.S. Atoian, G.I. Britvich, S.K. Chernichenko, et al. http://geant4.cern.ch

12. M. Derrick, D. Gacek, N. Hill, et al. Design and construction of the ZEUS barrel calorimeter // Nuclear An Improved Shashlyk Calorimeter // Nuclear Instruments and Methods in Physics Research A. 2008, v. 584, p. 291-303.

Article received 06.04.2021

\section{ВЫЧИСЛЕНИЕ РАДИУСА МОЛЬЕРА ДЛЯ РАЗЛИЧНЫХ КОНФИГУРАЦИЙ ЭЛЕКТРОМАГНИТНОГО СЭМПЛИНГ-КАЛОРИМЕТРА ЕСаL SPD NICA}

\section{В.Е. Ковтун, Т.В. Мальхина}

Одна из главных задач электромагнитной калориметрии установки SPD - эффективное $\pi^{0}-\gamma$-разделение в области 50 МеВ...10 ГэВ. Поэтому актуальной задачей является оптимизация конструкции ячеек модуля с целью улучшения физических параметров калориметра ECaL. Методом Монте-Карло (Geant4) определен радиус Мольера для различных конфигураций ячейки модуля калориметра. Полученные результаты будут учтены при дальнейшей разработке детектирующих систем ECaL SPD NICA.

\section{ОБЧИСЛЕННЯ РАДІУСА МОЛЬЕРА ДЛЯ РІЗНИХ КОНФІГУРАЦЙ ЕЛЕКТРОМАГНІТНОГО СЕМПЛІНГ-КАЛОРИМЕТРА ЕCaL SPD NICA}

\section{В.С. Ковтун, Т.В. Малихіна}

Одна $з$ головних задач електромагнітної калориметрії установки SPD - ефективне $\pi^{0}-\gamma$-розділення в області 50 МеВ...10 ГеВ. Тому актуальною задачею $є$ оптимізація конструкції комірок модуля 3 метою покращення фізичних параметрів калориметра ECaL. Методом Монте-Карло (Geant4) визначено радіус Мольєра для різних конфігурацій комірки модуля калориметра. Отримані результати будуть враховані під час подальшої розробки детектуючих систем ECaL SPD NICA. 